\title{
Butterflies on the brink: identifying the Australian butterflies (Lepidoptera) most at risk of extinction
}

Hayley M. Geyle ${ }^{1 *}$, Michael F. Braby ${ }^{2,3}$, Mick Andren ${ }^{4}$, Ethan P. Beaver ${ }^{5}$, Phil Bell ${ }^{6}$, Catherine Byrne ${ }^{7}$, Madelaine Castles ${ }^{8}$, Fabian Douglas ${ }^{9}$, Richard V. Glatz ${ }^{5,10,11}$, Bryan Haywood $^{12}$, Peter Hendry ${ }^{13,14}$, Roger L. Kitching ${ }^{15}$, Trevor A. Lambkin ${ }^{16}$, Cliff E. Meyer ${ }^{17}$, Michael D. Moore ${ }^{5}$, John T StL Moss ${ }^{13,14}$, Simon Nally ${ }^{18}$, Tim R. New ${ }^{19}$, Christopher M. Palmer $^{20}$, Ed Petrie $^{21}$, Josephine Potter-Craven ${ }^{22,23}$, Karen Richards ${ }^{23,24}$, Chris Sanderson ${ }^{25}$, Alex Stolarski ${ }^{26}$, Gary S. Taylor ${ }^{27}$, Matthew R. Williams ${ }^{28}$, John C.Z. Woinarski ${ }^{1}$ and Stephen T. Garnett ${ }^{1}$

${ }^{1}$ Threatened Species Recovery Hub, National Environmental Science Program, Research Institute for the Environment and Livelihoods, Charles Darwin University, Darwin, NT 0909, Australia.

${ }^{2}$ Division of Ecology and Evolution, Research School of Biology, The Australian National University, Acton, ACT 2601, Australia

${ }^{3}$ The Australian National Insect Collection, GPO Box 1700, Canberra, ACT 2601, Australia ${ }^{4}$ NSW Biodiversity, Conservation and Science, Coffs Harbour, NSW 2450, Australia.

${ }^{5}$ Biological and Earth Sciences, South Australian Museum, SA 5000, Australia.

${ }^{6}$ School of Natural Sciences, University of Tasmania, Hobart, Tasmania 7005, Australia.

${ }^{7}$ Tasmanian Museum and Art Gallery, Department of State Growth, Hobart, Tas 7000, Australia.

${ }^{8}$ Saving Our Species, Ecosystems and Threatened Species Team, North West Branch, Biodiversity and Conservation Division, Department of Planning, Industry and Environment, Dubbo, NSW 2830, Australia.

${ }^{9}$ Entomological Society of Victoria, Melbourne, Vic 3000, Australia.

${ }^{10}$ University of Adelaide, School of Agriculture, Food \& Wine, Urrbrae, SA 5064, Australia.

${ }^{11}$ D'Estrees Entomology \& Science Services, MacGillivray, SA 5223, Australia.

${ }^{12}$ Nature Glenelg Trust, Mt Gambier, SA 5290, Australia.

${ }^{13}$ Entomological Society of Queensland, Indooroopilly, Qld 4068, Australia.

${ }^{14}$ Butterfly and Other Invertebrates Club Inc., Runcorn, Qld 4113, Australia.

${ }^{15}$ Environmental Futures Research Institute, Griffith University, Nathan, Qld 4111, Australia. 
${ }^{16}$ School of Biological Sciences, The University of Queensland, St Lucia, Qld 4072, Australia.

1729 Silky Oak Ave, Moggill, Qld 4070, Australia.

${ }^{18}$ Australian Government Department of Agriculture, Water, and the Environment, Parkes ACT 2600.

${ }^{19}$ Department of Ecology, Environment and Evolution, La Trobe University, Vic 3086, Australia.

${ }^{20}$ Australian National Insect Collection, National Research Collections Australia, CSIRO, PO Box 1700, Canberra ACT 2601, Australia.

${ }^{21}$ Palm Cove, Qld 4879, Australia.

${ }^{22}$ Discipline of Geography and Spatial Sciences, University of Tasmania, Hobart, Tas 7005, Australia.

${ }^{23}$ Threatened Species Section, Threatened Species \& Conservation Programs Branch, Natural and Cultural Heritage Division, Department of Primary Industries, Parks, Water \& Environment, Hobart, Tas 7000, Australia.

${ }^{24}$ School of Natural Sciences, University of Tasmania, Hobart, Tas 7005, Australia.

${ }^{25}$ Research School of Biology, The Australian National University, Acton, ACT, 2601, Australia.

${ }^{26}$ Ento Search, Tailem Bend, SA 5260, Australia.

${ }^{27}$ Australian Centre for Evolutionary Biology and Biodiversity, and School of Biological Sciences, The University of Adelaide, North Terrace, Adelaide, SA 5005, Australia.

${ }^{28}$ Science and Conservation, Department of Biodiversity, Conservation and Attractions, Bentley Delivery Centre, WA 6983, Australia.

*hayley.geyle@cdu.edu.au

\title{
Running title
}

Butterflies on the brink

\begin{abstract}
The diversity and abundance of native invertebrates is declining globally, which could have significant consequences for ecosystem functioning. Declines are likely to be at least as severe as those observed for vertebrates, although often are difficult to quantify due to a lack of historic baseline data and limited monitoring effort. The Lepidoptera are well studied in
\end{abstract}


Australia compared with other invertebrates, so we know that some species are imperilled or declining. Despite this, few butterfly taxa are explicitly listed for protection by legislation.

Here we aim to identify the butterfly taxa that would most benefit from listing by determining the Australian butterflies at most immediate risk of extinction. We also identify the research and management actions needed to retain them. For 26 taxa identified by experts and various conservation schedules, we used structured expert elicitation to estimate the probability of extinction within 20 years (i.e. by 2040), and to identify key threatening processes, priority research and management needs. Collation and analysis of expert opinion indicated that one taxon, the laced fritillary (Argynnis hyperbius inconstans), is particularly imperilled, and that four taxa (Jalmenus eubulus, J. aridus, Hypochrysops piceatus and Oreisplanus munionga larana) have a moderate-high ( $>30 \%$ ) risk of extinction by 2040. Mapped distributions of the 26 butterflies revealed that most are endemic to a single state or territory, and that many occupy narrow ranges. Inappropriate fire regimes, habitat loss and fragmentation (through agricultural practices), invasive species (mostly through habitat degradation caused by weeds and rabbits) and climate change were the most prevalent threats affecting the taxa considered. Increased resourcing and management intervention will be required to prevent these extinctions. We provide specific recommendations for averting such losses.

\section{Key words}

Anthropogenic mass extinction crisis, biodiversity conservation, conservation management Delphi, expert elicitation, IDEA, insect decline, IUCN Red List, key threatening processes.

\section{INTRODUCTION}

Biodiversity is in the midst of a human-driven extinction crisis (Jenkins 2003; Pimm et al. 1995; Ceballos et al. 2015; Cardoso et al. 2020; Pimm et al. 2014; Woinarski et al. 2019). Modern extinctions have occurred at a rate that far exceeds the background rate estimated from the fossil record (Ceballos et al. 2015; Johnson et al. 2017), comparable in magnitude to the five previous mass extinctions that have occurred throughout Earth's history (Dirzo et al. 2014). Few of these studies have quantified the likely loss of invertebrates which constitute over $99 \%$ of global animal species diversity, and consequently, the true rate of biodiversity decline is likely to be severely underestimated (Régnier et al. 2015). 
Terrestrial invertebrates and their habitats are increasingly threatened by human disturbances (e.g. habitat loss and fragmentation, invasive species, inappropriate fire regimes and climate change; Sánchez-Bayo \& Wyckhuys 2019, 2021) leading to an overall pattern of decline in insect diversity and abundance globally (Wagner 2020). Dirzo et al. (2014) suggest that the rate of decline in abundance, species extinctions, and range contraction among terrestrial invertebrates are at least as severe as among vertebrates, estimating a global decline of $45 \%$ over 40 years (albeit with varying severity among taxonomic orders). van Klink et al. (2020) analysed 166 long-term surveys of insect assemblages across 1676 sites (four of which were located in Australia) to investigate geographic patterns of decline, finding that the evidence of decline was strongest for terrestrial insects in North America, and in some European regions. Indeed, in protected areas in Germany, Hallmann et al. (2017) estimated a seasonal decline of $76 \%$ in flying insect biomass over a 27 -year period (between 1989-2016), while in Britain, Thomas et al. (2004) measured declines in $71 \%$ of native butterflies over a 20 -year period (between 1970-1999).

Increasing levels of decline and possible extirpations in terrestrial native invertebrate communities are certain to have adverse effects on ecosystem functioning because invertebrates play a central role in many ecological processes, including pollination, herbivory, detrivory, nutrient cycling, and by providing a food source for higher trophic levels (Hallmann et al. 2017; Sands 2018; Taylor et al. 2018; Kitching et al. 2020). Accordingly, there is an urgent need to determine the cause(s) of these declines, understand the ramifications for ecosystems and ecosystem services, and implement appropriate management actions that aim to halt and reverse declines in those species at greatest risk of extinction (Samways et al. 2020).

The International Union for Conservation of Nature (IUCN) Red List of threatened species is the most widely used tool for measuring extinction risk to biodiversity globally (Rodrigues et al. 2006). But because it requires robust data on geographic range, population trends, threats, habitat and ecology (which are typically only available for a small minority of invertebrates from well-known groups, such as Lepidoptera and Odonata), the vast majority of the world's invertebrates have not had their conservation status evaluated (Régnier et al. 2015; Cardoso et al. 2011). Despite some attempts to better represent invertebrates on the IUCN Red List (e.g. by developing a "Sampled Red List Index" for butterflies, Lewis \& Senior 2011), less than $1 \%$ of the ca. 1.4 million taxa described globally have been assessed for inclusion 
(Régnier et al. 2015). This is in part because the original categories and criteria were designed explicitly for vertebrates (Mace et al. 2008; Cardoso et al. 2011), presenting challenges when applying the IUCN Red List to invertebrates. While there has been an extensive effort to increase the applicability of the criteria to other taxa (IUCN 2012), there are still limitations in their suitability for many invertebrate groups (Moir \& Brennan 2020; Kwak et al. 2020), such as the inability to adequately capture complex plant and ant host interactions that compound the difficulty of conserving many lepidoptera (e.g. Fiedler 2012; Ueda et al. 2016). That there have been many documented invertebrate extinctions of species that were not listed on the IUCN Red List (e.g. see Régnier et al. 2009; Braby 2019; James et al. 2019) suggests that to date such lists have had limitations for identifying and prioritising invertebrates at greatest risk of extinction. Furthermore, because the IUCN threat categories conflate declining populations and small populations, they do not readily distinguish among species on a rapid trajectory towards extinction from those that may persist in small numbers for long periods (Geyle et al. 2018; Dirzo et al. 2014), so listing a species within a particular IUCN Red List category says nothing about when a species is likely to go Extinct, only that it is at risk of doing so.

Despite recent progress in Australia (New 2010; New \& Sands 2002; Harvey et al. 2011; Barton \& Moir 2015; Braby 2018), many challenges remain for invertebrate conservation and management (Sands 2018; Taylor et al. 2018). Invertebrates are generally poorly known and under-studied (Eisenhauer et al. 2019), and much of their vast biodiversity remains undescribed (Taylor et al. 2018). This, coupled with limited resources (e.g. scientific expertise and funds), has made it difficult to assess and hence address their conservation needs (Sands 2018). Furthermore, recent advancements in conservation assessments (Braby 2018; Braby et al. 2018) have not translated into statutory lists. For example, despite being one of the better-studied and more charismatic invertebrate groups (Fleishman \& Murphy 2009; Taylor et al. 2018), only ten butterflies (species and subspecies) are currently recognised as threatened under Australian environmental legislation (the Environmental Protection and Biodiversity Conservation Act 1999 [EPBC]) (Taylor et al. 2018), equating to $\sim 1.6 \%$ of the recognised 614 Australian butterfly taxa (species and subspecies) (AFD 2020). Of those that are formally listed, most are without management or recovery plans (Sands 2018), while several other species that are likely to be threatened have either not been formally evaluated for listing, or there is insufficient information for them to meet eligibility criteria (Sands 2018). 
Australian terrestrial invertebrate biodiversity is substantial, highly endemic, and characterised by numerous ancient lineages, relicts and evolutionary radiations (Andersen 2016; Austin et al. 2004; Cranston 2010; Raven \& Yeates 2007; Kristensen et al. 2015). It is also under increasing stress, and likely to be declining rapidly (Sands 2018; New 2018; New et al. 2021). To meet commitments made by the Australian Government—along with signatories to the Convention on Biological Diversity - to avoid further extinctions (Department of Environment and Energy 2016; United Nations 2015), we must first identify the species at most immediate risk, and identify actions that should reduce that risk.

Here, we used structured expert elicitation to estimate the probability of extinction in the next 20 years for the subset of Australia's butterflies identified by experts to be at high risk of extinction. We chose to assess extinction risk in butterflies because they are relatively wellstudied in Australia (unlike most other Lepidoptera, and indeed most invertebrates; Lewis \& Senior 2011), and because there is a large enough group of interested experts with sufficient knowledge to make an informed assessment about their current and future conservation outlook. We acknowledge that this relatively substantial evidence base for butterflies, and the relatively large constituency of experts, renders this group potentially unrepresentative of the plight of invertebrates more generally. However, the factors driving butterfly decline may be typical of those affecting other invertebrate groups (e.g. see Leather 2018), so it is plausible that the rate and extent of declines in butterflies may also be representative of other invertebrate groups, for which comparable analyses would be severely constrained by far greater knowledge gaps.

We mapped the distributions of the most threatened butterfly taxa to identify priority regions for Australian butterfly conservation. We then collated information on likely threatening processes, with the overall aim of identifying key research and management objectives for averting future extinction. Our approach follows estimates of imminent extinction risk among Australian birds and mammals (Geyle et al. 2018), freshwater fish (Lintermans et al. 2020), and terrestrial squamates (Geyle et al. 2020). Note that this assessment preceded the 2019-20 wildfires in Australia, which are likely to have severely worsened the conservation outlook for many species.

\section{MATERIALS AND METHODS}




\section{Initial taxon selection}

More than 40 experts were invited to participate in this project, selected on the basis of their experience and knowledge of Australian butterflies and their conservation. This included amateurs among whom resides much of the knowledge of butterfly natural history in Australia, as well as experts from academic institutions, state and federal government offices and agencies and non-government organisations. Overall, 28 experts (including representatives from every state and territory) were actively involved in the project (all of whom are co-authors), either by participating in a workshop, taking part in the expert elicitation and/or by providing detailed information about one or more species of Australian butterfly.

We produced a preliminary list of Australian butterflies at high risk of extinction within the next 20 years based on published information and various conservation schedules (e.g. state and federal conservation documents and threatened listing advices). We then undertook detailed email correspondence and workshop discussions with our expert panel to identify a candidate list of species that could be lost to extinction within our 20-year timeframe of interest, with a particular focus on unlisted taxa (i.e. the aim was to consider only those taxa that were candidates for possible extinction by 2040). We chose 20 years as an arbitrary period over which might reasonably be assessed, and which might reasonably be influenced by policy and management changes made today. All experts were given the opportunity to nominate additional taxa for consideration, which they believed warranted inclusion. After several weeks of detailed discussions, a list of 26 species and subspecies was finalised for assessment (Table 1).

\section{Structured expert elicitation}

A total of 21 experts participated in a workshop to discuss the conservation of Australian butterflies, to finalise the list of taxa most likely to become extinct in the next 20 years, and to estimate the likelihood of extinction for those taxa. We used structured expert elicitation for obtaining estimates of butterfly extinction probability, using a procedure based largely on the Delphi (Burgman et al. 2011) and IDEA methods (Hemming et al. 2018). Each of these approaches has been developed in an attempt to reduce the incidence of some commonly encountered biases in expert elicitation processes (Martin et al. 2012). Our adapted approach followed five main steps: 
1. Before the workshop, experts were provided with a draft conservation account of relevant information on each taxon based on published literature and unpublished information obtained from taxon specialists. Draft accounts included information on biology, habitat requirements, population parameters, geographic range, historical and predicted rates of decline (where available), and threats. The accounts were available on the day of the workshop, and a summary of the information was presented for each taxon. Experts were given the opportunity to provide greater context through discussion of the information, to seek clarification from taxon specialists (if present), and to identify any missing information that might influence the risk of extinction.

2. Based on the information presented in the draft accounts and discussions, experts were asked to provide, for each taxon, an initial estimate of the probability of extinction in the wild within the next 20 years, scaled from $0-100 \%$, assuming current levels and characteristics of management ("Round 1" scores). In addition, experts provided a level of confidence in each of their estimates (very low, $\leq 20 \%$; low, $21-$ $40 \%$; moderate, $41-60 \%$; high, $61-80 \%$; or very high, $\geq 80 \%$ ), and were encouraged to provide justification for their scores. Participants were asked not to discuss their scores with each other (as each individual assessment was to be treated as independent).

3. Individual estimates of extinction probability were compiled during a break in the workshop. We then calculated summary statistics (including mean, median, range), and provided participants with graphs displaying the summary data so that they could see where their estimates conformed or otherwise to those of the rest of the group. Experts were encouraged to engage in a general conversation about the results, and to highlight taxa for which they would consider modifying their estimates of extinction probability based on this discussion. For several taxa, it was noted that additional information from taxon specialists (who were not able to attend the workshop) was required to inform estimates. Detailed minutes were taken during this discussion for later reference.

4. Following the workshop, the individual assessments of extinction probability and their associated confidence were modelled using a linear mixed effects model. We controlled for individual experts consistently underestimating or overestimating likelihood of extinction by specifying their identity as random intercepts. We specified a variance structure in which the variance increased with the level of uncertainty associated with each estimate of likelihood of extinction. Confidence 
classes of 'very low', 'low', 'moderate', 'high' and 'very high' were converted to uncertainty scores of 90, 70, 50, 30 and 10\% respectively. This model allowed us to predict the probability of extinction (with $95 \%$ confidence intervals) for each taxon (as in Geyle et al. 2018). Predicted probabilities of extinction and 95\% confidence intervals, the summary statistics and the detailed workshop minutes were provided to all workshop participants, and also to additional experts who were unable to attend (but have key knowledge on one or more of the taxa under consideration). All experts were then asked to review the results, while noting any concerns about the spread of estimates given for a particular taxon, or the rankings of extinction probability. Each participant was then given the opportunity to clarify information about the presented data, introduce further relevant information that may justify either a greater or lesser risk of extinction, and to cross-examine new information via email.

5. Participants were then asked to provide a second, final assessment of the probability of extinction (and associated confidence) for each taxon, from which the results were finalised ("Round 2" scores).

\section{Estimating the number of taxa likely to become extinct in the next 20 years}

The predicted probabilities of extinction for each of the 26 butterflies (assessed by the experts) were summed to estimate the number of taxa (from this subset of Australian butterflies) likely to become extinct in the next 20 years (as per Geyle et al. 2018).

\section{Testing for concordance among expert assessments}

We measured the level of agreement among experts in the relative ranking of the most imperilled butterflies using Kendall's Coefficient of Concordance ( $\square$ ) (Kendall \& Babinton Smith 1939). This test allows for comparison of multiple outcomes (i.e. assessments made by multiple experts), whilst making no assumptions about the distribution of data. Average ranks were used to correct for the large number of tied values in the dataset, and ranks were compared only for the 16 experts who assessed all 26 taxa.

\section{Geographic distribution of the most imperilled butterflies}

We mapped the distribution of the most imperilled butterflies according to their presence in each Interim Biogeographic Regionalisation for Australia (IBRA) bioregion (DAWE 2015) using distributional data (range maps) compiled from Braby (2016). 


\section{Key threatening processes}

Key threats to each taxon were derived from the published literature, conservation listing advices (where applicable), the Action Plan for Australian Butterflies (BAP, Sands \& New 2002) and from unpublished information and observations of taxon experts. All threats were categorised using the IUCN Threats Classification Scheme (Version 3.2, IUCN 2020c). We used this information to determine the number and proportion of taxa threatened by various threat types. Note that this assessment of threats included both ongoing threats, and putative threats that could plausibly impact the species under consideration within the time frame of interest (i.e. 20 years).

\section{Conservation priorities}

For each of the butterflies under consideration, we identified relevant research and management actions considered necessary for reducing extinction risk using various published and unpublished sources (BAP, conservation listing advices, published literature and expert opinion). Research included actions that involve seeking improved knowledge of status, understanding of threats, or those aimed at improving management options (i.e. actions required to fill knowledge gaps that reduce uncertainty about which management actions to implement, and how to implement them) (Gillespie et al. 2020). Research actions were categorised using the IUCN Research Needed Classification Scheme (Version 2.0, IUCN 2020b). Management actions included those that, based upon current knowledge, are likely to lead, directly or indirectly, to tangible reductions in a species' extinction risk (i.e. evidence suggests that such actions will ameliorate the impact of a threatening process, or increase the number and/or size of populations) (Gillespie et al. 2020). Management actions were categorised using the IUCN Conservation Actions Classification Scheme (Version 2.0, IUCN 2020a).

Monitoring is crucial for testing recommendations from research and evaluating whether management interventions are achieving their intended aim (Robinson et al. 2018). However, the type of monitoring required will depend upon the target species and specific management interventions (Woinarski et al. 2017). Therefore, we assume here that monitoring will occur in conjunction with research and management interventions (i.e. we do not consider actions relating solely to monitoring in the absence of management intervention). Likewise, all of the butterflies considered here would benefit from formal conservation planning (i.e. through recovery plans and/or area-based management plans), and accordingly, actions relating solely 
to conservation planning are not considered. This should not be taken as discounting the importance of monitoring and recovery planning, as each is a critical component of conserving threatened species.

\section{RESULTS}

Only six of the taxa considered had been designated as threatened under the EPBC Act (as of February 2020), with a further two nominations in preparation (by some of the authors listed here). A far larger number of species (20) were recognised as threatened under the relevant legislation from one or more of the states or territories in which they are known to occur (Table 1). A small proportion of the remaining 588 recognised taxa were considered to be threatened at either a national or state level in the Action Plan for Australian Butterflies (see Appendix 1, Sands \& New 2002); however, these taxa were considered unlikely to go extinct in the next 20 years by our expert panel. Braby and Williams (2016) calculated the number of species likely to be missing from the Australian butterfly fauna (i.e. those that are undescribed, described but not recognised, or known but not yet recorded from Australia), and estimated that 42 butterfly taxa are yet to be discovered.

\section{Expert elicitation, extinction probabilities and the number of species likely to become extinct}

Collation and analysis of expert opinion (Round 2 scores) indicated that one of the 26 taxa considered, the laced fritillary (Argynnis hyperbius inconstans) is at extremely high risk (likelihood $>90 \%$ ) of becoming extinct within the next 20 years (Table 2); indeed, it may already be so, with apparently no confirmed specimen records of the butterfly since 2001 (Lambkin 2017). The most recent putative record of the species is a sighting of a single male made near Port Macquarie, NSW on 13 April 2015 by A. Moore (pers. comm.). An additional four taxa had moderate-high probabilities of extinction (30-50\%) (Table 2). Summing across the extinction risk values assigned by the experts to the 26 taxa assessed, we estimated that five taxa are likely to become extinct by 2040 unless management improves. There was a reasonable and highly significant degree of conformity among experts in their assessments of extinction risk $(\square=0.3, \square=<0.001)$.

\section{Geographic distribution of the most imperilled Australian butterflies}

Of the 26 taxa considered in our assessment, all are endemic to Australia, although two taxa (A. hyperbius inconstans and the apollo jewel Hypochrysops apollo apollo) have other 
subspecies beyond the shores of Australia (but note that A. hyperbius inconstans may be a distinct species endemic to Australia (Lambkin 2017)). Eighteen of the butterflies are endemic to a single state or territory (Table 1). The remaining eight taxa are known historically from two or three neighbouring states or territories (Table 1), but in some cases are believed to have been locally extirpated. For example the small bronze azure (Ogyris otanes otanes) is most likely extirpated in New South Wales (NSW) and possibly Victoria, with extant populations confirmed only from SA, whereas the eastern bronze azure $(O$. halmaturia) has almost certainly been extirpated from a formerly wide area in Victoria and now persists precariously at only three sites in South Australia (Braby \& Douglas 2008; R. Glatz, unpublished data). Victoria is home to the highest number of taxa $(n=9)$, with the majority occurring in the Murray Darling Depression, Victorian Midlands, Naracoorte Coastal Plain and South Eastern Highlands bioregions (Fig. 1). Queensland and NSW each have seven taxa, mostly occurring in the Brigalow Belt (north and south), South Eastern Queensland and Wet Tropics bioregions (Fig. 1).

\section{Key threatening processes}

Natural system modifications were the most prevalent threats to the butterflies, affecting 21 of the taxa considered (Fig. 2). Within this broad category, inappropriate fire regimes, including both increases and decreases (suppression or absence) in fire frequency and/or intensity, impacted the most taxa at 19. Four butterflies (three of which were also affected by fire) were impacted by dams and water management, particularly drainage of wetlands and swamps (Appendix S1). Other important threats included agriculture (notably clearance and fragmentation of habitat associated with non-timber crops and domestic livestock, affecting 17 of the taxa considered, and invasive species (particularly introduced grasses, introduced herbivores - namely European rabbits Oryctolagus cuniculus - and introduced invertebrates) affecting 14 of the taxa considered (Appendix S1). Climate change is likely to affect almost half of the taxa considered ( $n=11)$ (Fig. 2), with increases in temperature, the duration and frequency of drought, and sea level rise being potentially catastrophic in the future (Appendix $\mathrm{S} 1)$.

\section{Conservation priorities}

All 26 taxa considered are likely to benefit from further surveys, allowing for more precise estimates of occupancy, geographic distribution (extent of occurrence and area of occupancy) and population size (Fig 3a). Likewise, all 26 taxa should benefit from further research to 
assess the impacts of their known or putative key threatening processes (Fig 3a). Specifically, most of the butterflies considered $(n=18)$ require a greater understanding of the role of disturbance (e.g. fire) in their ecology, or in the ecology of their attendant ants and host plants (Appendix S2). There is some uncertainty about the ecological requirements for 10 taxa (including their critical habitats, interactions with attendant ants, biology and life cycle), warranting further investigation (Fig 3, Appendix S2). For six of the butterflies considered, further work to clarify their taxonomic status is required (Fig. 3a), as this could have important implications for their conservation. For example, if a taxon is "split" (i.e. where it is found to be two or more species), each new species would have a smaller geographic distribution and population size than previously thought, which may elevate their threatened status Eight butterflies were also identified as possible candidates for research into the feasibility of ex-situ conservation (including captive breeding) (Fig. 3a, Appendix S2).

The most important management actions to reduce the risks of extinction were related to education and awareness (a priority for all 26 taxa under consideration), land/water management (a priority for 21 of the taxa considered), and land/water protection (a priority for 18 of the taxa considered) (Fig. 3b). Community engagement, including site visits, installation of signage, and discussions with private landholders and land managers, was considered to be a priority management action for all 26 taxa considered. Within the broader category of land/water management, implementation of an appropriate fire management strategy was the most common action assigned (a priority for 18 of the taxa considered), followed by invasive species control (particularly weeds and invasive herbivores) (a priority for 13 taxa) (Appendix S3). Within the broader category of land/water protection, the most common action assigned was site protection, particularly identifying sites of high conservation value for priority protection (Appendix S3).

\section{DISCUSSION}

The abundance and diversity of invertebrates is declining globally (Sánchez-Bayo \& Wyckhuys 2019, 2021; Wagner 2020; van Klink et al. 2020). Given increasing concerns of continued decline (Dirzo et al. 2014), escalating pressures associated with ongoing threatening processes (Sánchez-Bayo \& Wyckhuys 2019; Samways et al. 2020), and the ecological importance of maintaining invertebrate biodiversity (Hallmann et al. 2017; Sands 2018), it is crucial that extinction risk is recognised in a timely manner to allow for implementation of management responses aimed at preventing extinctions. Here, we used 
structured expert elicitation to help redress this issue for Australian butterflies, by forecasting which, and how many, taxa are at high risk of extinction.

Overall, experts estimated the butterflies under consideration to have moderate probabilities of extinction within the next 20 years, with an average estimate of $18 \%$ across the 26 considered taxa. One butterfly, A. hyperbius inconstans was considered to have a very high extinction probability ( $\sim 94 \%$ ). Four other taxa, the pale imperial hairstreak (Jalmenus eubulus), the inland hairstreak (J.aridus), the bulloak jewel (Hypochrysops piceatus) and the Marrawah skipper (Oreisplanus munionga larana), were estimated to have probabilities of extinction of $30-50 \%$. Although there are no confirmed extinctions of Australian butterflies since European colonisation, the pace of modern insect extinctions is suspected to have surpassed that of vertebrates by a large margin (Sánchez-Bayo \& Wyckhuys 2019). However, this is obfuscated by a paucity of historical data on trends in population size and geographical range size in many regions (including Australia). In areas where population trajectories have been assessed, the majority of taxa have declined, including not only specialist taxa (i.e. those with narrow ecological requirements, such as dependence on a single host plant), but also generalist species that were once very common (Sánchez-Bayo \& Wyckhuys 2019, 2021). This suggests that there are likely to have been earlier undetected extinctions, and that future extinctions are inevitable without rapid and targeted intervention.

Insects have been declining in many parts of the world for several decades, a phenomenon which is likely to be affecting ecosystem functioning (Hallmann et al. 2017). Yet despite their importance, these losses have been largely unreported in the wider community. In Australia, there is little long-term monitoring data to support anecdotal reports of decline (Braby 2019). Few of the taxa considered in this study have had their distributions (extent of occurrence and area of occupancy) accurately mapped, and even fewer have robust data on population sizes or trends. This is primarily due to a lack of resources (including qualified entomologists and butterfly conservation biologists) and funding for conservation activities (Taylor et al. 2018; Sanderson et al. 2021). Nevertheless, for many of the taxa considered here (and others, e.g. Ogyris idmo; Williams et al. 2020), there has been a clear contraction in range (attributable to localised extinctions or extirpations of populations). Population monitoring has also been accorded insufficient priority in Australian biodiversity research and management (Lindenmayer \& Gibbons 2012; Legge et al. 2018), contributing further to a general lack of data on Australian butterfly populations. 
The butterflies considered in this study share many common threats, the most prevalent of which are natural system modifications (e.g. inappropriate fire regimes or surface water abstraction), habitat loss and fragmentation for agriculture, invasion by exotic species, and climate change. These threats are largely consistent with those identified to have contributed to the reduction of insect numbers nationally and globally (Sands 2018; Sánchez-Bayo \& Wyckhuys 2019). Indeed, many of the taxa considered in this study are associated with habitats that have historically been cleared at a high rate (e.g. old-growth Brigalow woodlands of central Qld and the old-growth mangrove forests of coastal NSW and Qld), and almost all of the taxa considered are suffering from secondary impacts associated with fragmentation and isolation. Notably, four of the five most imperilled butterflies occur in Qld (with two also known from NSW) on the eastern coast of Australia, an area currently undergoing high rates of land clearing. This region has been identified as one of 11 deforestation hotspots by the World Wildlife Fund (Schwartz 2015). This suggests that those species are highly likely to have undergone substantial historical declines (e.g. J. eubulus) (Eastwood et al. 2008). For several taxa currently persisting in these already highly modified landscapes, land-use change and habitat loss for development is ongoing. For example, extant and potential breeding sites used by the mangrove ant-blue (Acrodipsas illidgei) are threatened by further coastal development, particularly so in areas where the butterfly occurs outside of conservation reserves. Similarly, there is still extensive clearing of critical habitat used by the Tasmanian chaostola skipper (Antipodia chaostola leucophaea) as a result of increased urbanisation, particularly around Hobart, Tasmania. This current, and any future, loss of critical resources must inevitably cause further declines.

Another key aspect facing the most imperilled butterflies is that all of the taxa are ecological specialists (most are monophagous, being dependent on a single species of host plant or host ant). In fact, 13 taxa considered in this study are co-dependent on a specific species of ant. In addition, almost all of the taxa are narrow-range endemics, with very small geographical distributions. The only exception to this is J. eubulus, although this species has lost $>95 \%$ of its habitat, and so has suffered from substantial contractions to its' area of occupancy (Eastwood et al. 2008). Host specificity and ecological complexity, together with limited spatial extent, could be key predictors of vulnerability in Australian butterflies. Thus, using a traits-based approach, it may be possible to identify and prioritise additional taxa which might be of high extinction risk. 
We identified many common research and management priorities among the butterflies considered, each of which were largely congruent with the three main recommendations of the BAP: (1) further exploration to detect any previously unknown populations, whose discovery may affect other priorities and needs, (2) acquisition, or conservation measures, to secure critical sites, and (3) aspects of restoration and management of degraded habitats (Sands \& New 2002). The most important research actions included further surveys to allow for more precise estimates of geographic distribution and population size to be determined, and further research to assess key threatening processes (particularly relating to climate change and inappropriate fire regimes) and their relative and compounding impacts. For some taxa, more research is required to determine their ecological requirements (including critical habitat types, interactions with attendant ants, biology and life cycle), while others require further research to resolve taxonomic issues.

Many of the taxa considered here are likely to benefit from implementation of an appropriate fire management strategy, invasive species control, and the identification of sites of high conservation value for priority protection. The most important conservation actions, however, were related to education and awareness (identified as a priority for all of the taxa considered) and land/water management and protection. Community engagement has the potential to raise general awareness, to locate additional populations of threatened taxa, to encourage key stakeholders to contribute to the implementation of conservation actions, and to foster community ownership regarding conservation. This engagement is critical, given that much of the work required to recover threatened Australian butterflies, including ecological restoration, management and monitoring falls into the hands of citizen scientists and non-government organisations (Sands \& New 2002). Platforms like Butterflies Australia, a smart-phone app and website (https://www.butterflies.org.au) launched recently for citizen scientists (Sanderson et al. 2021), provide a great step towards achieving some of the key goals in invertebrate conservation. This initiative was designed specifically to remedy the data deficiency of butterflies in Australian conservation policy and scientific research. It is likely to help increase community awareness, to encourage community participation (where observational data can be collected in a format suitable for scientific analysis), and to increase the availability of scientifically robust observational data on butterflies (which, previously has not been readily accessible) (Sanderson et al. 2021). The launch of the app and website was accompanied by a series of workshops around Australia to train citizen 
scientists on butterfly identification and survey methods, how to use the app and web portal, and to explain how this data can be used to assist in butterfly conservation.

We did not consider actions relating solely to recovery planning and monitoring, as the need for these is influenced by the circumstances of the individual target species and their ecological contexts, and the specific research and management interventions required. We stress, however, that both components are critical for ensuring the ongoing persistence of Australia's most threatened butterflies. Scheele et al. (2019) demonstrated for vertebrates that taxa with national recovery plans were more likely to be monitored, and that the monitoring was more likely to be of higher quality. In fact, even taxa with lapsed recovery plans scored highly for monitoring quality. Implementing effective monitoring can be challenging, particularly so for naturally rare species or those that are in rapid decline (and consequently are difficult to detect). Recovery plans (when funded and implemented) provide a useful tool for which clear guidelines on monitoring can be incorporated (Braby 2018). Robinson et al. (2018) discuss five key principles requiring consideration when designing monitoring programs for threatened species: (1) engaging people; (2) integrating monitoring with management; (3) planning, designing and implementing a fit-for-purpose monitoring program; (4) ensuring good data management; and (5) communicating the value of monitoring. These principles provide a clear framework in which to implement robust monitoring of threatened species, and should be considered as part of the recovery of each of Australia's most imperilled butterflies.

\section{CONCLUSIONS AND RECOMMENDATIONS}

This study predicts that five Australian butterflies may become extinct in the next two decades without immediate and sustained remedial action. To reduce the risk of this happening, the following package of national management and policy responses is urgently required:

1. Implement research and management actions (i.e. those outlined in Appendix S2 and S3). These should not be delayed until the taxa under consideration are formally listed as threatened under the EPBC Act.

2. Highly threatened but currently unlisted taxa should be listed formally as threatened under national and state/territory legislative processes, with recovery plans developed, and recovery teams established. The butterfly taxa identified in this study are obvious candidates. 
3. Habitat protection is the most important aspect of butterfly conservation. Relevant habitats important to imperilled Australian butterflies should therefore be listed as critical habitat under the EPBC Act. For the taxa considered here, this includes coastal mangrove communities in Qld and NSW, coastal grasslands and associated paperbark (Melaleuca) wetlands in eastern Australia, saline sedgelands in southern Australia and Tasmania, summits of hilltops and of inland sand dunes, inland native grasslands and heathlands, and inland communities of old-growth brigalow.

4. Update the BAP (Sands \& New 2002) to assess the current conservation status and trend of all butterfly taxa of conservation concern (not just the most imperilled). Provide the information required for listing, immediate guidance on actions, and enable coordination of recovery efforts for nationally threatened butterflies.

5. Recognising that most of the taxa considered here are narrow-range endemics, and that conservation of Australian biodiversity is a shared responsibility between national and state/territory governments, ensure state governments provide more leadership in the conservation management of imperilled butterflies restricted to their jurisdictions.

6. Promote the amateur study, collection, and sharing of information about butterflies and ensure this is not perversely impeded by conservation policy. In particular, butterfly collecting (i.e. by non-professional lepidopterists) has contributed significantly to the knowledge of the taxonomy, distribution, biology and conservation of butterflies in Australia, and will remain a vital source of information relevant to butterfly conservation and management. As such, prohibition of the collection of listed butterfly taxa is likely to have adverse effects on butterfly conservation. For the exceptionally rare taxa for which over-collecting was identified as a possible threat (included in the category "biological resource use", see Fig. 2), measures must be put in place to ensure maximum responsibility for their conservation. The 'code of conduct' presented in the BAP to facilitate and link the different priorities of collectors and conservation authorities is still relevant and influential today, and should be applied widely across Australia.

7. Ensure that amendments to policy and legislation adequately consider the knowledge and management needs of invertebrate conservation, that regulatory protections of critical habitat are strengthened and that there is adequate support for development and implementation of Recovery Planning. 
The probability of further extinctions of Australian butterflies is high, and may have been underestimated here. Our assessment was undertaken prior to the 2019-2020 Black Summer bushfires, and consequently, we do not consider the impacts of the fires on the taxa considered, or on other taxa that were omitted from this study (which may now be at high risk of extinction). It is still too early to determine the impact (both short- and long-term) of the fires at a species level. Nevertheless, and notwithstanding the fire impacts, our results suggest that up to five taxa could become extinct by 2040 under current management regimes. Only urgent action, enhanced policy and planning, increased community awareness and a betterresourced conservation response will prevent future extinctions in Australian butterflies.

\section{ACKNOWLEDGMENTS}

The preparation of this paper, including data collation and analysis, was supported by the Australian Government through the National Environmental Science Program's Threatened Species Recovery Hub. We thank Ian Leiper for preparing the distribution map, Peter Valentine for providing early feedback on the project, Tony Moore for sharing his unpublished data, and Melinda Moir and an anonymous referee for helpful and constructive comments on the manuscript.

\section{REFERENCES}

AFD. 2020. Australian Biological Resources Study. Australian Faunal Directory. Available at: https://biodiversity.org.au/afd/home [accessed September 2020].

Andersen AN. 2016. Ant megadiversity and its origins in arid Australia. Austral Entomology 55, 132-137.

Austin AD, Yeates DK, Cassis G, et al. 2004. Insects 'Down Under'- Diversity, endemism and evolution of the Australian insect fauna: examples from select orders. Australian Journal of Entomology 43, 216-234.

Barton P \& Moir ML. 2015. Invertebrate indicators and ecosytem restoration. In 'Indicators and Surrogates of Biodiversity and Environmental Change'. (Eds. D. Lindenmayer, P. Barton and J. Pierson), pp. 59-68. CSIRO Publishing, Clayton South. 
Braby MF. 2016. The Complete Field Guide to Butterflies of Australia. Second Edition. CSIRO Publishing: Melbourne.

Braby MF. 2018. Threatened species conservation of invertebrates in Australia: an overview. Austral Entomology 57, 173-181.

Braby MF. 2019. Are insects and other invertebrates in decline in Australia? Austral Entomology 58, 471-477.

Braby MF \& Douglas F. 2008. The nomenclature, taxonomy and conservation status of Ogyris waterhouseri (Bethune-Baker, 1905) stat. nov. (Lepidoptera: Lycaenidae), a threatened butterfly from southern Australia. Australian Journal of Entomology 47, 315-329.

Braby MF, Franklin DC, Bisa DE, et al. 2018. Atlas of Butterflies and Diurnal Moths in the Monsoon Tropics of Northern Australia. ANU Press: Canberra.

Braby MF \& Williams MR. 2016. Biosystematics and conservation biology: critical scientific disciplines for the management of insect biological diversity. Austral Entomology 55, $1-17$.

Burgman MA, McBride M, Ashton R, et al. 2011. Expert status and performance. PLOS ONE 6, e22998.

Cardoso P, Barton PS, Birkhofer K, et al. 2020. Scientists' warning to humanity on insect extinctions. Biological Conservation 242, 108426.

Cardoso P, Borges PAV, Triantis KA, Ferrández MA \& Martín JL. 2011. Adapting the IUCN Red List criteria for invertebrates. Biological Conservation 144, 2432-2440.

Ceballos G, Ehrlich PR, Barnosky AD, García A, Pringle RM \& Palmer TM. 2015. Accelerated modern human-induced species losses: entering the sixth mass extinction. Science Advances 1, e1400253. 
Cranston PS. 2010. Insect biodiversity and conservation in Australasia. Annual Review of Entomology 55, 55-75.

DAWE. 2015. IBRA Subregion Australia Version 7.0 - ARC. Bioregional Assessment Source Dataset. Available at: https://www.environment.gov.au/land/nrs/science/ibra\#ibra [accessed Decemeber 2020].

Department of Environment and Energy. 2016. The National Threatened Species Strategy. Department of the Environment and Heritage, Canberra, Australia.

Dirzo R, Young HS, Galetti M, Ceballos G, Isaac NJB \& Collen B. 2014. Defaunation in the Anthropocene. Science 345, 401-406.

Eastwood R, Braby MF, Schmidt DJ \& Hughes JM. 2008. Taxonomy, ecology, genetics and conservation status of the pale imperial hairstreak (Jalmenus eubulus) (Lepidoptera : Lycaenidae): a threatened butterfly from the Brigalow Belt, Australia. Invertebrate Systematics 22, 407-423.

Eisenhauer N, Bonn A \& A. Guerra C. 2019. Recognizing the quiet extinction of invertebrates. Nature Communications 10, 50.

Fiedler K. 2012. The host genera of ant-parasitic Lycaenidae butterflies: a review. Psyche 2012, 153975 .

Fleishman E \& Murphy DD. 2009. A realistic assessment of the indicator potential of butterflies and other charismatic taxonomic groups. Conservation Biology 23, 1109 1116.

Geyle HM, Tingley R, Amey AP, et al. 2020. Reptiles on the brink: identifying the Australian terrestrial snake and lizard species most at risk of extinction. Pacific Conservation Biology, doi:10.1071/PC19037. 
Geyle HM, Woinarski JCZ, Baker GB, et al. 2018. Quantifying extinction risk and forecasting the number of impending Australian bird and mammal extinctions. Pacific Conservation Biology 24, 157-167.

Gillespie GR, Roberts DR, Hunter D, et al. 2020. Status and priority conservation actions for Australian frog species. Biological Conservation 247, 108543.

Hallmann CA, Sorg M, Jongejans E, et al. 2017. More than 75 percent decline over 27 years in total flying insect biomass in protected areas. PLOS ONE 12, e 0185809.

Harvey MS, Rix MG, Framenau VW, et al. 2011. Protecting the innocent: studying shortrange endemic taxa enhances conservation outcomes. Invertebrate Systematics 25, 110.

Hemming V, Burgman MA, Hanea AM, McBride MF \& Wintle BC. 2018. A practical guide to structured expert elicitation using the IDEA protocol. Methods in Ecology and Evolution 9, 169-180.

IUCN. 2012. IUCN Red List Categories and Criteria: Version 3.1. Second edition. Gland, Switzerland and Cambridge, UK: IUCN iv+32pp.

IUCN. 2020a. IUCN Conservation Actions Classification Scheme, Version 2.0. Available at: https://www.iucnredlist.org/resources/conservation-actions-classification-scheme [accessed September 2020].

IUCN. 2020b. IUCN Research Needed Classification Scheme, Version 2.0. Available at: https://www.iucnredlist.org/resources/research-needed-classification-scheme [accessed September 2020].

IUCN. 2020c. IUCN Threats Classification Scheme, Version 3.2. Available at: https://www.iucnredlist.org/resources/threat-classification-scheme [accessed September 2020]. 
James DJ, Green PJ, Humphreys WF \& Woinarski JCZ. 2019. Endemic species of Christmas Island, Indian Ocean. Records of the Western Australian Museum 35, 55-114.

Jenkins M. 2003. Prospects for biodiversity. Science 302, 1175-1177.

Johnson CN, Balmford A, Brook BW, et al. 2017. Biodiversity losses and conservation responses in the Anthropocene. Science 356, 270-275.

Kendall MG \& Babinton Smith B. 1939. The problem of m rankings. The Annals of Mathematical Statistics 10, 275-287.

Kitching RL, Dahlsjö CAL \& Eggleton P. 2020. Invertebrates and the complexity of tropical ecosystems. Biotropica 52, 207-214.

Kristensen NP, Hilton DJ, Kallies A, et al. 2015. A new extant family of primitive moths from Kangaroo Island, Australia, and its significance for understanding early Lepidoptera evolution. Systematic Entomology 40, 5-16.

Kwak ML, Heath ACG \& Cardoso P. 2020. Methods for the assessment and conservation of threatened animal parasites. Biological Conservation 248, 108696.

Lambkin TA. 2017. Argynnis hyperbius inconstans Butler, 1873 (Lepidoptera: Nymphalidae: Heliconiinae): a review of its collection history and biology. Australian Entomologist 44, 223-268.

Leather SR. 2018. "Ecological Armageddon" - more evidence for the drastic decline in insect numbers. Annals of Applied Biology 172, 1-3.

Legge S, Scheele BC, Woinarski JCZ, et al. 2018. Summary: monitoring extent and adequacy for threatened species. In 'Monitoring Threatened Species and Ecological Communities'. (Eds S Legge, DB Lindenmayer, NM Robinson, BC Scheele, DM Southwell and BA Wintle) pp. 127-133. (CSIRO Publishing: Melbourne). 
Lewis O \& Senior M. 2011. Assessing conservation status and trends for the world's butterflies: the Sampled Red List Index approach. Journal of Insect Conservation 15, 121-128.

Lindenmayer D \& Gibbons P. 2012. (Eds.) Biodiversity monitoring in Australia. CSIRO Publishing: Melbourne.

Lintermans M, Geyle HM, Beatty S, et al. 2020. Big trouble for little fish: identifying Australian freshwater fishes in imminent risk of extinction. Pacific Conservation Biology, https://doi.org/10.1071/PC19053.

Mace GM, Collar N, J., Gaston KJ, et al. 2008. Quantification of extinction risk: IUCN's system for classifying threatened species. Conservation Biology 22, 1424-1442.

Martin TG, Burgman MA, Fidler F, et al. 2012. Eliciting expert knowledge in conservation science. Conservation Biology 26, 29-38.

Moir ML \& Brennan KEC. 2020. Incorporating coextinction in threat assessments and policy will rapidly improve the accuracy of threatened species lists. Biological Conservation 249, 108715.

New TR. 2010. Butterfly conservation in south-eastern Australia: progress and prospects. Springer Science \& Business Media.

New TR. 2018. Promoting and developing insect conservation in Australia's urban environments. Austral Entomology 57, 182-193.

New TR \& Sands DPA. 2002. Narrow-range endemicity and conservation status: interpretations for Australian butterflies. Invertebrate Systematics 16, 665-670.

New TR, Sands DPA \& Taylor GS. 2021. Roles of roadside vegetation in insect conservation in Australia. Austral Entomology 60, (in press).

Pimm SL, Jenkins CN, Abell R, et al. 2014. The biodiversity of species and their rates of extinction, distribution, and protection. Science 344, 1246752. 
Pimm SL, Russell GJ, Gittleman JL \& Brooks TM. 1995. The future of biodiversity. Science 269, 347-350.

Raven PH \& Yeates DK. 2007. Australian biodiversity: threats for the present, opportunities for the future. Australian Journal of Entomology 46, 177-187.

Régnier C, Achaz G, Lambert A, Cowie RH, Bouchet P \& Fontaine B. 2015. Mass extinction in poorly known taxa. Proceedings of the National Academy of Sciences 112, 77617766.

Régnier C, Fontaine B \& Bouchet P. 2009. Not knowing, not recording, not listing: numerous unnoticed mollusk extinctions. Conservation Biology 23, 1214-1221.

Robinson NM, Legge S, Scheele BC, et al. 2018. Essential principles to guide monitoring of threatened biodiversity. In 'Monitoring Threatened Species and Ecological Communities'. (Eds S. Legge, D.B. Lindenmayer, N.M. Robinson, B.C. Scheele, D. Southwell, and B. Wintle). pp. 427-438. (CSIRO Publishing: Melbourne.)

Rodrigues A, Pilgrim J, Lamoreux J, Hoffmann M \& Brooks T. 2006. The value of the IUCN Red List for conservation. Trends in Ecology and Evolution 21, 71-6.

Samways MJ, Barton PS, Birkhofer K, et al. 2020. Solutions for humanity on how to conserve insects. Biological Conservation 242, 108427.

Sánchez-Bayo F \& Wyckhuys KAG. 2019. Worldwide decline of the entomofauna: a review of its drivers. Biological Conservation 232, 8-27.

Sánchez-Bayo F \& Wyckhuys KAG. 2021. Further evidence for a global decline of the entomofauna. Austral Entomology 60, (in press).

Sanderson C, Braby MF \& Bond S. 2021. Butterflies Australia: a national citizen science database for monitoring changes in the distribution and abundance of Australian butterflies. Austral Entomology 60, (in press). 
Sands DPA. 2018. Important issues facing insect conservation in Australia: now and into the future. Austral Entomology 57, 150-172.

Sands DPA \& New TR. 2002. The Action Plan for Australian Butterflies. Environment Australia: Canberra.

Scheele BC, Legge S, Blanchard W, et al. 2019. Continental-scale assessment reveals inadequate monitoring for threatened vertebrates in a megadiverse country. Biological Conservation 235, 273-278.

Schwartz J. 2015. 11 of the world's most threatened forests. World Wildlife Fund. Available at: https://www.worldwildlife.org/stories/11-of-the-world-s-most-threatened-forests [accessed August 2020].

Taylor GS, Braby MF, Moir ML, et al. 2018. Strategic national approach for improving the conservation management of insects and allied invertebrates in Australia. Austral Entomology 57, 124-149.

Thomas JA, Telfer MG, Roy DB, et al. 2004. Comparative losses of British butterflies, birds, and plants and the global extinction crisis. Science 303, 1879-1881.

Ueda S, Komatsu T, Itino T, Arai R \& Sakamoto H. 2016. Host-ant specificity of endangered large blue butterflies (Phengaris spp., Lepidoptera: Lycaenidae) in Japan. Scientific Reports 6, 36364 .

United Nations. 2015. Transforming our world: the 2030 agenda for sustainable development. Resolution adopted by the General Assembly on 25 September 2015. UN General Assembly, New York.

van Klink R, Bowler DE, Gongalsky KB, Swengel AB, Gentile A \& Chase JM. 2020. Metaanalysis reveals declines in terrestrial but increases in freshwater insect abundances. Science 368, 417-420. 
Wagner DL. 2020. Insect Declines in the Anthropocene. Annual Review of Entomology 65, 457-480.

Williams AAE, williams MR \& Heterick BE. 2020. Notes on the distribution, habitat, behaviour and flight times of the Large Bronze Azure, Ogyris idmo (Hewitson, 1862) (Lepidoptera: Lycaenidae), a rare myrmecophilous butterfly from south-western Western Australia. The Australian Entomologist 47, 221-217.

Woinarski JCZ, Braby MF, Burbidge AA, et al. 2019. Reading the black book: the number, timing, distribution and causes of listed extinctions in Australia. Biological Conservation 239, 108261.

Woinarski JCZ, Garnett ST, Legge SM \& Lindenmayer DB. 2017. The contribution of policy, law, management, research, and advocacy failings to the recent extinctions of three Australian vertebrate species. Conservation Biology 31, 13-23. 


\section{SUPPORTING INFORMATION}

2

3 Appendix S1. Key threats affecting the 26 butterflies at greatest risk of extinction,

4 categorised using the IUCN Threats Classification Scheme (IUCN, 2020. IUCN Threats

5 Classification Scheme, Version 3.2. Available at:

6 https://www.iucnredlist.org/resources/threat-classification-scheme [accessed September

7 2020])

8

9 Appendix S2. Priority research actions for the 26 butterflies at greatest risk of extinction, 10 categorised using the IUCN Research Needed Classification Scheme (IUCN, 2020. IUCN

11 Research Needed Classification Scheme, Version 2.0. Available at:

12 https://www.iucnredlist.org/resources/research-needed-classification-scheme [accessed

13 September 2020]

14

Appendix S3. Priority management actions for the 26 butterflies at greatest risk of extinction, categorised using the IUCN Conservation Actions Classification Scheme (IUCN, 2020.

17 IUCN Conservation Actions Classification Scheme, Version 2.0. Available at:

18 https://www.iucnredlist.org/resources/conservation-actions-classification-scheme [accessed

19 September 2020] 
Table 1. The scientific and common names, state/territory of occurrence (Queensland, QLD; New South Wales, NSW; Victoria, VIC; Tasmania, TAS; South Australia, SA; Western Australia, WA; Northern Territory, NT), and the International Union for Conservation of Nature Red List (IUCN), Environmental Protection and Biodiversity Conservation Act, 1999 (EPBC), and relevant State/Territory conservation status listings for the most imperilled Australian butterflies (based on structured expert elicitation). Critically Endangered, CR; Endangered, EN; Vulnerable, VU;

Threatened, Thr (VIC); Priority 1, P1 (WA); Not listed, NL.

\begin{tabular}{|c|c|c|c|c|}
\hline Taxon & $\begin{array}{c}\text { Occurrence } \\
\text { (State/Territory) }\end{array}$ & IUCN & EPBC & State/Territory \\
\hline $\begin{array}{l}\text { Acrodipsas illidgei (Waterhouse \& Lyell, 1914). Mangrove ant-blue, Illidges } \\
\text { ant-blue }\end{array}$ & QLD, NSW & EN & NL & VU (QLD), NL (NSW) \\
\hline $\begin{array}{l}\text { Argynnis hyperbius inconstans Butler, 1873. Laced fritillary, Australian } \\
\text { fritillary }\end{array}$ & QLD, NSW & NL & $\mathrm{CR}$ & EN (QLD), NL (NSW) \\
\hline Croitana arenaria arenaria E.D. Edwards, 1979. Inland grass-skipper & NT & NL & NL & NL (NT) \\
\hline Exometoeca nycteris Meyrick, 1888. Western flat & WA & NL & NL & NL (WA) \\
\hline
\end{tabular}


Heteronympha cordace wilsoni Burns, 1948. Bright-eyed brown

Hypochrysops apollo apollo Miskin, 1891. Apollo jewel

Hypochrysops piceatus Kerr, Macqueen \& D.P.A. Sands, 1969. Bulloak jewel

Jalmenus aridus Graham \& Moulds, 1988. Inland hairstreak

Jalmenus eubulus Miskin, 1876. Pale imperial hairstreak

Ocybadistes knightorum Lambkin \& Donaldson, 1994. Black grass-dart

Ogyris sp. aff. aenone (Waterhouse, 1902). Sapphire azure (southern population)

Ogyris halmaturia (Tepper, 1890). Eastern bronze azure

Ogyris iphis doddi (Waterhouse \& Lyell, 1914). Dodd's azure, orange-tipped azure

Ogyris otanes otanes (C. \& R. Felder, 1865). Small bronze azure

Ogyris otanes sublustris M.R. Williams \& Hay, 2001. Western dark azure, small bronze azure

Ogyris subterrestris petrina Field, 1999. Arid bronze azure

Ogyris subterrestris subterrestris Field, 1999. Arid bronze azure

Oreisplanus munionga larana L.E. Couchman, 1962. Marrawah skipper, alpine sedge-skipper

\begin{tabular}{|c|c|c|c|}
\hline VIC, SA & NL & NL & Thr (VIC), NL (SA) \\
\hline QLD & NL & NL & VU (QLD) \\
\hline QLD & NL & NL & EN (QLD) \\
\hline WA & NL & NL & $\mathrm{P} 1$ (WA) \\
\hline QLD, NSW & NL & NL & VU (QLD), CR (NSW) \\
\hline NSW & $\mathrm{EN}$ & NL & EN (NSW) \\
\hline QLD & NL & NL & NL (QLD) \\
\hline VIC, SA & NL & NL & Thr (VIC), NL (SA) \\
\hline NT & NL & NL & EN (NT) \\
\hline NSW, VIC, SA & NL & NL & NL (NSW, VIC SA) \\
\hline WA & NL & NL & NL (WA) \\
\hline WA & NL & $\mathrm{CR}$ & CR (WA) \\
\hline VIC, SA & NL & NL & Thr (VIC), NL (SA) \\
\hline TAS & NL & VU & EN (TAS) \\
\hline
\end{tabular}


Oreixenica latialis theddora L.E. Couchman, 1953. Small alpine xenica

Oreixenica ptunarra L.E. Couchman, 1953. Ptunarra xenica, ptunarra brown

Paralucia spinifera E.D. Edwards \& Common, 1978. Purple copper, Bathurst copper

Telicota eurychlora Lower, 1908. Southern sedge-darter

^As Hesperilla flavescens
VIC

TAS

NL NL

Thr (VIC)

NSW

NL EN

VU (TAS)

EN

VU

EN (NSW)

QLD, NSW, VIC

NL

NL

NL (QLD, NSW), Thr (VIC) 
Table 2. The estimated probability of extinction (EX) by 2040 (in the wild) for the 26 Australian butterflies considered to be most imperilled.

29 Likelihoods of extinction are based on structured expert elicitation (with lower/upper 95\% confidence intervals) and are ranked from highest to

30 lowest probability of extinction.

\begin{tabular}{|c|c|c|c|c|}
\hline Rank & Taxon & EX & Lower $95 \% \mathrm{CI}$ & Upper $95 \% \mathrm{CI}$ \\
\hline 1 & Argynnis hyperbius inconstans laced fritillary, Australian fritillary & 0.94 & 0.89 & 0.97 \\
\hline 3 & Hypochrysops piceatus bulloak jewel & 0.37 & 0.24 & 0.53 \\
\hline 5 & Jalmenus aridus inland hairstreak & 0.30 & 0.15 & 0.50 \\
\hline 6 & Ogyris sp. aff. aenone sapphire azure (southern population) & 0.28 & 0.16 & 0.44 \\
\hline 7 & Ogyris subterrestris subterrestris arid bronze azure & 0.28 & 0.16 & 0.44 \\
\hline 8 & Croitana arenaria arenaria inland grass-skipper & 0.22 & 0.12 & 0.36 \\
\hline 9 & Heteronympha banksii nevina Banks' brown & 0.19 & 0.10 & 0.32 \\
\hline 10 & Heteronympha cordace wilsoni bright-eyed brown & 0.18 & 0.10 & 0.30 \\
\hline 11 & Ogyris subterrestris petrina arid bronze azure & 0.15 & 0.08 & 0.26 \\
\hline 12 & Candalides noelkeri golden-rayed blue & 0.13 & 0.07 & 0.23 \\
\hline
\end{tabular}




\begin{tabular}{|c|c|c|c|c|}
\hline Rank & Taxon & EX & Lower $95 \% \mathrm{CI}$ & Upper $95 \% \mathrm{CI}$ \\
\hline 13 & Antipodia chaostola leucophaea Tasmanian chaostola skipper, heath sand-skipper & 0.11 & 0.06 & 0.19 \\
\hline 15 & Oreixenica ptunarra ptunarra xenica, ptunarra brown & 0.09 & 0.05 & 0.17 \\
\hline 17 & Ogyris iphis doddi Dodd's azure, orange-tipped azure & 0.07 & 0.03 & 0.14 \\
\hline 18 & Hesperilla flavescens flavescens yellow sedge-skipper & 0.07 & 0.03 & 0.14 \\
\hline 19 & Exometoeca nycteris western flat & 0.07 & 0.03 & 0.14 \\
\hline 22 & Ogyris otanes otanes small bronze azure & 0.06 & 0.03 & 0.11 \\
\hline 23 & Ocybadistes knightorum black grass-dart & 0.05 & 0.03 & 0.10 \\
\hline 24 & Telicota eurychlora southern sedge-darter & 0.03 & 0.01 & 0.05 \\
\hline 25 & Paralucia spinifera purple copper, Bathurst copper & 0.03 & 0.01 & 0.05 \\
\hline 26 & Hypochrysops apollo apollo apollo jewel & 0.02 & 0.01 & 0.04 \\
\hline
\end{tabular}


Figure 1. The total number of imperilled Australian butterflies occurring in each Interim

Biogeographic Regionalisation for Australia (IBRA) bioregion (SA Department of

Environment, Water and Natural Resources 2015). Data are presented for the 26 most imperilled butterflies (derived using structured expert elicitation). Occurrence data were collated from Braby (2016).

Figure 2. The number of imperilled Australian butterflies affected by different threats types, categorised using the IUCN Threats Classification scheme (Version 3.2, IUCN 2020c). Threat data are provided for the 26 most imperilled butterflies (based on structured expert elicitation). The total number of taxa affected by each broad threat category is provided in parentheses. Note that natural system change includes fire and fire suppression, and weather refers to extreme weather events. See Supplementary Material S1 for a breakdown of the threat categories and for detailed notes for individual taxa.

Figure 3. The number of (a) priority research actions, and (b) priority management actions identified for the 26 most imperilled Australian butterflies (derived using structured expert elicitation), and categorised using the IUCN Research Needed and Management Actions Classification Schemes (Versions 2.0, IUCN 2020b, a). The total number of taxa for which each of the broad research and management action categories were assigned is provided in parentheses. Note that "Other actions" in (a) refers to research to determine how to mitigate particular threats (e.g. whether ex-situ breeding is possible). See Supplementary Materials S2 and S3 for a breakdown of the action categories and for detailed notes for individual taxa. 


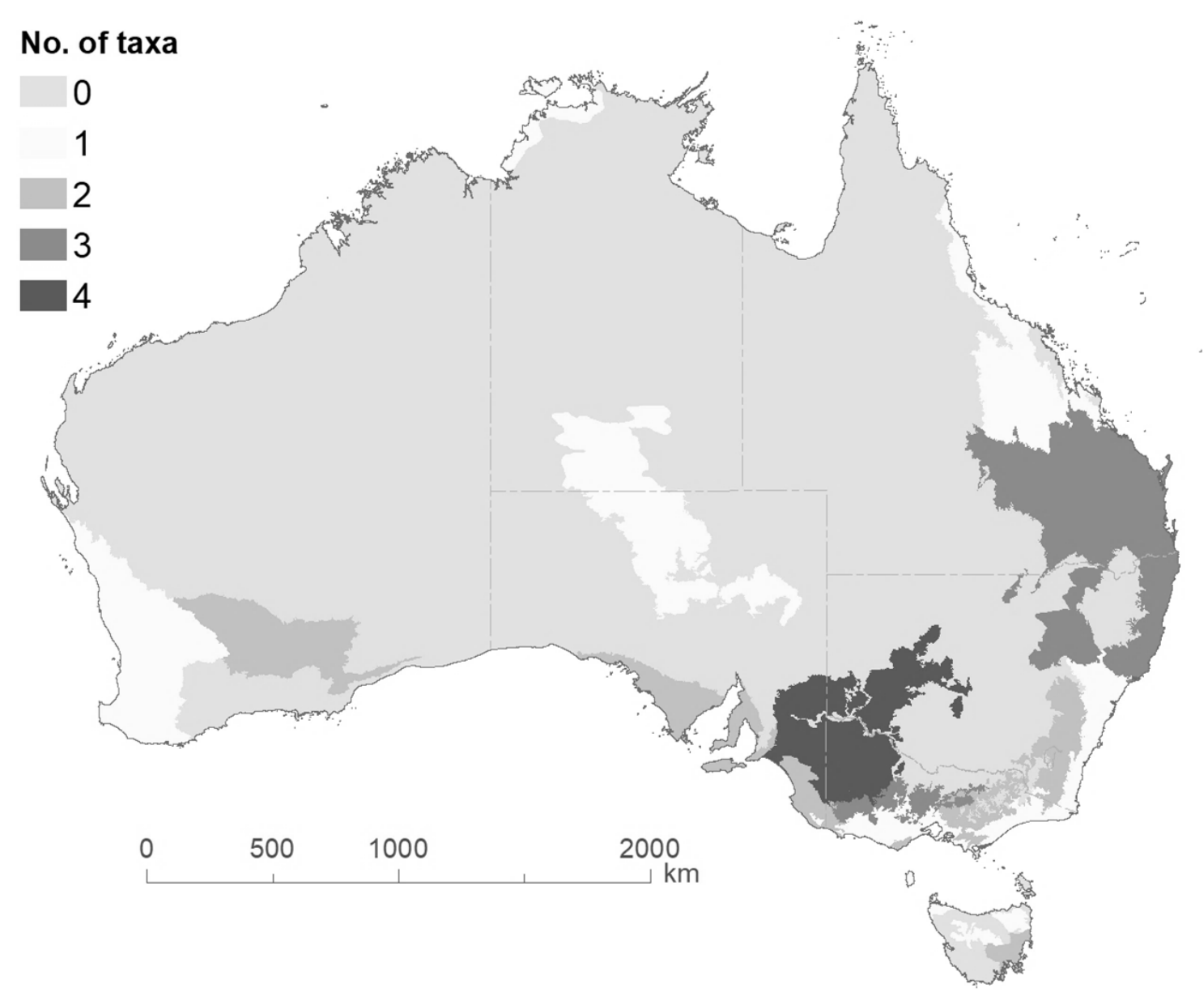

55 Figure 1. The total number of imperilled Australian butterflies occurring in each Interim

56 Biogeographic Regionalisation for Australia (IBRA) bioregion (SA Department of

57 Environment, Water and Natural Resources 2015). Data are presented for the 26 most

58 imperilled butterflies (derived using structured expert elicitation). Occurrence data were

59 collated from Braby (2016). 


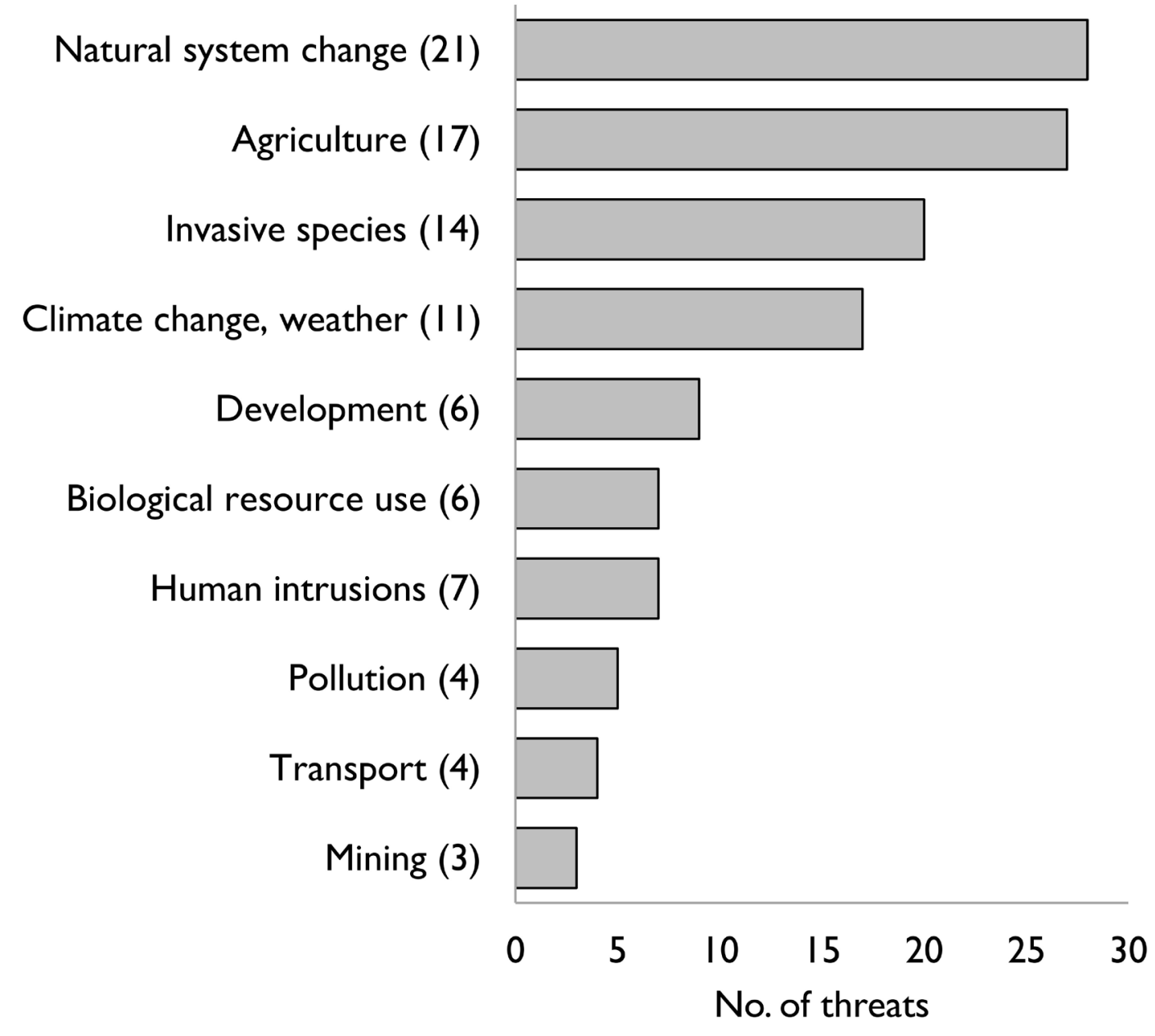

60 Figure 2. The number of imperilled Australian butterflies affected by different threats types, 61 categorised using the IUCN Threats Classification scheme (Version 3.2, IUCN 2020c).

62 Threat data are provided for the 26 most imperilled butterflies (based on structured expert 63 elicitation). The total number of taxa affected by each broad threat category is provided in 64 parentheses. Note that natural system change includes fire and fire suppression, and weather 65 refers to extreme weather events. See Supplementary Material S1 for a breakdown of the 66 threat categories and for detailed notes for individual taxa. 


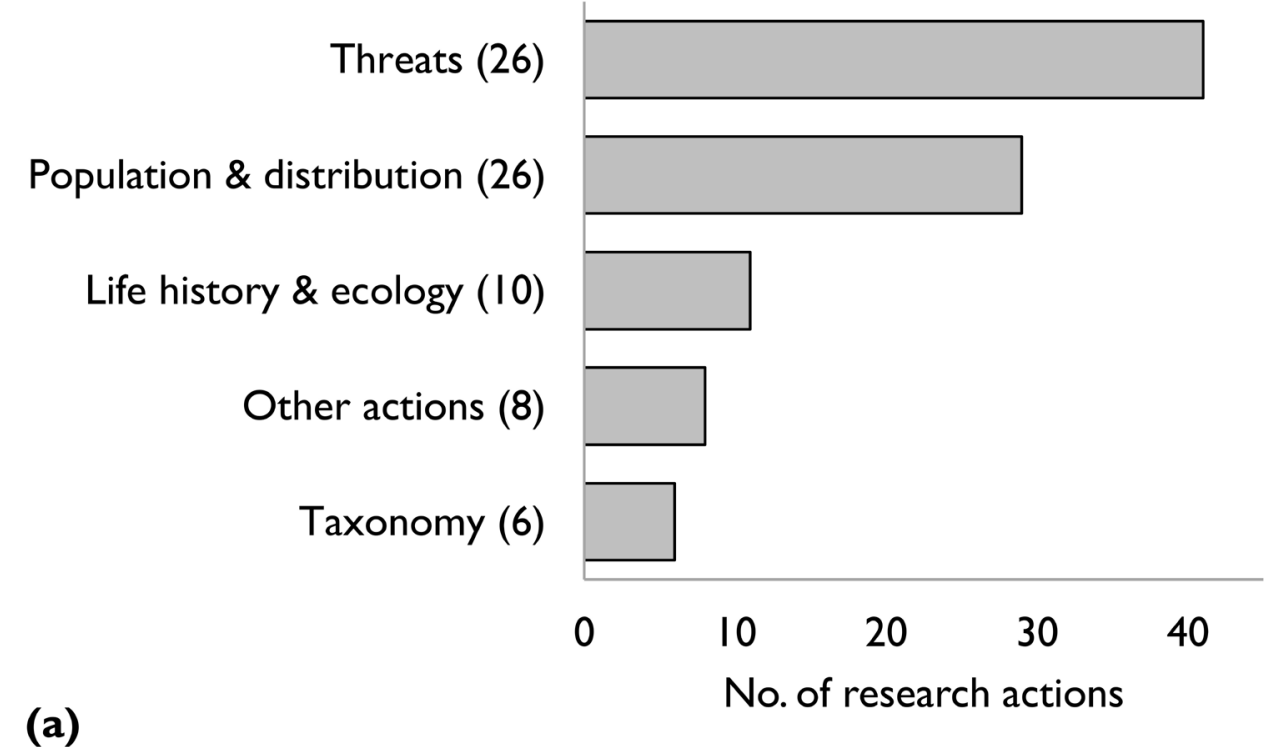

Education \& awareness (26)

Land management (2I)

Land protection (18)

Species management (8)

Law \& policy (I)

(b)
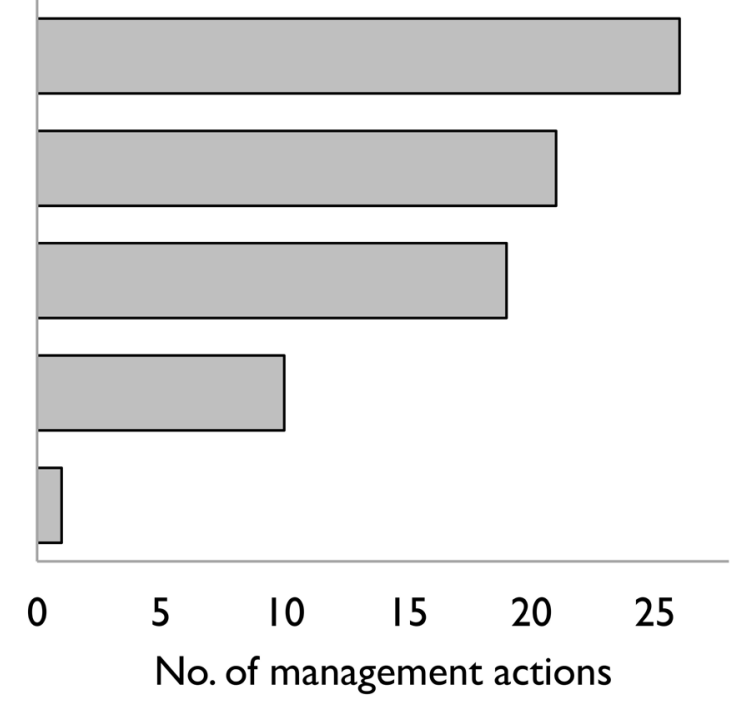

67 Figure 3. The number of (a) priority research actions, and (b) priority management actions 68 identified for the 26 most imperilled Australian butterflies (derived using structured expert 69 elicitation), and categorised using the IUCN Research Needed and Management Actions 70 Classification Schemes (Versions 2.0, IUCN 2020b, a). The total number of taxa for which 71 each of the broad research and management action categories were assigned is provided in 72 parentheses. Note that "Other actions" in (a) refers to research to determine how to mitigate 73 particular threats (e.g. whether ex-situ breeding is possible). See Supplementary Materials S2 74 and S3 for a breakdown of the action categories and for detailed notes for individual taxa. 